\title{
Detecting the antibacterial activity of green synthesized silver (Ag) nanoparticles functionalized with ampicillin (Amp)
}

\section{Israa Ali Zaidan Al-Ogaidi}

Department of Biotechnology, College of Science, Baghdad University, Baghdad, Iraq

Received 6/ 3/2016

Accepted $9 / 5 / 2016$

(i) $\Theta(9$

EY No ND This work is licensed under a Creative Commons Attribution-Non Commercial-No Derivatives 4.0 International License

\begin{abstract}
:
In the current study, synthesis and characterization of silver nanoparticles (AgNPs) before and after functionalization with ampicillin antibiotic and their application as anti-pathogenic agents towards bacteria were investigated. AgNPs were synthesized by a green method from $\mathrm{AgNO}_{3}$ solution with glucose subjected to microwave radiation. Characterization of the nanoparticles was conducted using UVVis spectroscopy, scanning electron microscopy (SEM), zeta potential determination and Fourier transform infrared (FTIR) spectroscopy. From SEM analysis, the typical silver nanoparticle particle size was found to be $30 \mathrm{~nm}$ and Zeta potential measurements gave information about particle stability. Analysis of FTIR patterns and UV-VIS spectroscopy confirmed the production of nanosilver particles. The activity of produced silver NP was tested against three pathogens (Escherichia coli, Staphylococcus aureus, and Acinetobacter baumannii) in both liquid and solid growth medium. AgNPs presented potential antibacterial activity, against tested bacteria. Ag and Ag-AMP nanoparticles were detected to have penitent antimicrobial. The optical density (OD) of the culture solution and measuring zones of inhibition were used to monitor the growth of bacteria in liquid and solid growth medium respectively
\end{abstract}

Key words: Silver nanoparticles, biosynthesis, antibacterial, glucose, microwave

\section{Introduction:}

In the recent years different bacterial strains have developed resistance to conventional antimicrobial drugs, such strains include multi-drugresistant isolates of Staphylococcus aureus, Acinetobacter baumanii and Escherichia coli [1] . The rapid spread of these isolates and the dangerous infections caused by them require the urge to find a replacement for the treatment of these MDR isolates derived the medical community to use them as novel antimicrobial agents. These new replacements must have the ability to interact and block microbial targets [2]. Silver nanoparticles recently used as antibacterial agents, the mechanism of action of AgNPs summarized by; $\mathrm{Ag}$ ions are released in aqueous solutions which cause the antimicrobial effect [3]. 
However; silver NPs have a toxic effect on the prokaryotic and eukaryotic cells and have a damaging effect on the DNA $[4,5]$. One of the methods that have developed is the functionalizing of biomolecules on the nanoparticles, such as the functionalizing of antibiotics on Ag NPs which as suggested by [3] they found that it can efficiently improve the antimicrobial effect of both Ag NPs and ampicillin antibiotic even in treating resistance isolated in the present investigation we constructed spherical silver nanoparticle using green method by reducing $\mathrm{AgNO}_{3}$ with glucose and microwave assistant to avoid toxicity of chemical reduction [6]. The produced Ag NPs were functionalized with ampicillin [3]. And the antibacterial effect of Ag and Ag-Amp against Staphylococcus aureus, Acinetobacter baumanii and Escherichia coli tested [7]. This study aimed to use nanomaterials to achieve antibacterial activity against MDRs isolates on the bacterial DNA through the following objectives: Synthesis of Ag NPs using green methods, functionalize $\mathrm{Ag}$ with Amp, characterization of nanoparticles before and after functionalization and test activity of $\mathrm{Ag}$ and $\mathrm{Ag}$-AMP against multidrug resistance isolated.

\section{Material and method:}

Synthesis of Silver nanoparticles

Sliver nanoparticles were prepared with some modification in Tollens' method ,in brief, mixing $\mathrm{AgNO}_{3}(2 \mathrm{mM})$ and $\mathrm{NaOH}(2 \mathrm{mM})$ lead to produce silver oxide that converted to the complex of silver ammonia by adding (10 $\mathrm{mM})$ ammonia solution.10mMof glucose was added to the reaction in a commercial microwave oven for $60 \mathrm{~s}$. Greenish-yellow color representing the formation of AgNP [6].

\section{Procedure for functionalization of $\mathbf{A g}$ nanoparticles with ampicillin}

Thioether in the structure of ampicillin work as an important to silver nanoparticles. $2.12 * 10^{4} \mathrm{M}$ of ampicillin was used to functionalize AgNPs after incubated it with $24 \mathrm{hr}$,after that particles were washed and centrifuged a number of times to remove unbind ampicillin. Particles were resuspended with $0.01 \mathrm{M}$ sodium citrate at $\mathrm{pH} 7$ and stored in the dark at $4^{\circ} \mathrm{C}$.The activity of functionalized silver nanoparticles was verified after wash and suspended in fresh media with buffer $0.02 \mathrm{M}$ sodium citrate $\mathrm{pH} 7$

\section{Characterization of nanoparticles before and after functionalization :}

Silver nanoparticles before and after functionalization with ampicillin were tested by using UV-visible absorbance spectrophotometer.As well as stability of ampicillin bound to the surface of AgNP was monitored for several weeks using Surface plasmon resonance (SPR) spectra of AgNP. The nanoparticles have been detected with SEM (using a Jeol $2010 \mathrm{~F}$ apparatus operating at $200 \mathrm{kV}$ (JEOL Ltd., Akishima-shi, Japan), $10 \mu \mathrm{l}$ of nanoparticle colloidal were deposited on glass coated with gold. The sample was dried overnight before observation .From SEM image, the size and shape were determined

Determination of the antibacterial activity of the Ag and Ag-Amp nanoparticles (Sahu,2013)

Strains of Escherichia coli, S.aureus and A.baumannii bacteria grew in Luria-Bertani (LB) medium containing $4.0 \mathrm{~g}$ peptone, $2.0 \mathrm{~g}$ yeast extract, $5.0 \mathrm{~g} \mathrm{NaCl}$ and $400 \mathrm{~mL} \mathrm{H}_{2} \mathrm{O}$ of which $\mathrm{pH}$ value was adjusted to 7.2-7.5 with $1 \mathrm{~mol} \mathrm{~L}^{-1} \mathrm{NaOH}$ before autoclaving. We then added $6.8 \mathrm{~g}$ agar to $1 \mathrm{~L}$ of $\mathrm{LB}$ medium, producing $\mathrm{LB}$ agar. The bacteria were inoculated in the 
LB medium in a self-regulating thermostat for $6 \mathrm{~h}$ at $37^{\circ} \mathrm{C}$. One milliliter original bacterial inoculum was added into $9 \mathrm{~mL} 0.9 \%$ normal saline and they were diluted to $106 \mathrm{cfu} \mathrm{mL}-1$ (colony forming unit, cfu), then inoculated into LB broth for 12 hour at $37^{\circ} \mathrm{C}$. Once the standard culture were prepared 2 methods were used to study the antibacterial activity [7].

\section{Agar disks diffusion test}

Antimicrobial activity of AgNPs and Ag-Amp as antibiotic against Staphylococcus aureus, E. coli and A.baumannii has been evaluated by disc diffusion method. This method was performed in Luria Bertani (LB) medium solid agar Petri dish. In brief, 6 $\mathrm{mm}$ well impregnated with different concentrations of silver nanoparticles and Ag-Amp separately and were placed on $S$. aureus, E. coli and A.baumannii cultured agar plate samples and were placed on S. aureus and E. coli cultured agar plate. Agar plate was then incubated for $24 \mathrm{~h}$ at $37^{\circ} \mathrm{C}$ and inhibition zone was monitored [8].

\section{Measurement of minimum inhibitory concentration (MIC)}

AgNPs was added in LB medium, respectively. Each bacterium culture S. aureus E. coli and A.baumannii was controlled at $10^{5}-10^{6}$ $\mathrm{CFU} / \mathrm{mL}$ and incubated at $37^{\circ} \mathrm{C}$.To establish the antimicrobial activity of silver nanoparticles on the bacterial growth, the minimum inhibitory concentration of nanosilver shapes for these bacteria were determined by optical density of the bacterial culture solution containing different concentration of Ag NPs after 24h. All of the experiments (MIC) were triplicated, on three different days [9].

\section{AgNP-AMP antibacterial effect}

The rate that AgNP and AgNPAMP killed ampicillin- resistant bacteria was determined. Three ampicillinresistant strains included in this experiment were E. coli, S.aureus and A.bomanii isolate. Disc diffusion method was used to test antibacterial activity of AgNP-AMP as previously mentioned at Agar disks diffusion test.

\section{Characterization of functionalized nanoparticles surfaces UV-visible spectrometer}

The UV-visible absorption spectra were measured at 200-1200 nm with spectrometer used as easy method to estimate the diameter and shape of nanoparticles. The UV-visible absorption spectra revealed that there was observable shift in the LSPR bands before and after functionalized $\mathrm{Ag}$ with Amp [10].

\section{Fourier transformed infrared radiation (FTIR)}

For fourier transformed infrared radiation (FTIR) spectroscopy measurements AgNP powder sample was pre- pared by centrifuging the synthesized AgNP solution at 10,000 rpm for $15 \mathrm{~min}$. The solid residue layer which contains AgNP was redispersed and washed in sterile deionized water for three times to remove the unattached biological impurities. The pure residue was then dried perfectly in an oven overnight at $65^{\circ} \mathrm{C}$. Thus obtained powder was subjected to FTIR measurements carried out on a PerkinElmer Spectrum-One instrument at a resolution of $4 \mathrm{~cm}^{-1}$ in $\mathrm{KBr}$ pellets.

\section{Zeta potential measurements}

Zeta potential measurements were obtained using the Zeta sizer Nanoseries ZS90 (Malvern Instruments, Worcestshire, UK) the freshly prepared colloidal AgNPs and Ag-Amp were measured by zeta potential to determine stability and particle size. 


\section{Results and discussion}

Synthesis and Characterization of $\mathbf{A g}$ nanoparticles by glucose and microwave Visualization of color:

The yellowish brown color of AgNPs in watery solution indicate the formation of AgNPs owing to excitation of the resonance of surface plasmon [3]. AgNPs developed by reduction of $\mathrm{Ag}^{+}$ in the presence of ammonia and glucose that lead to change color from pale to the yellowish brown as shown in figure (1).
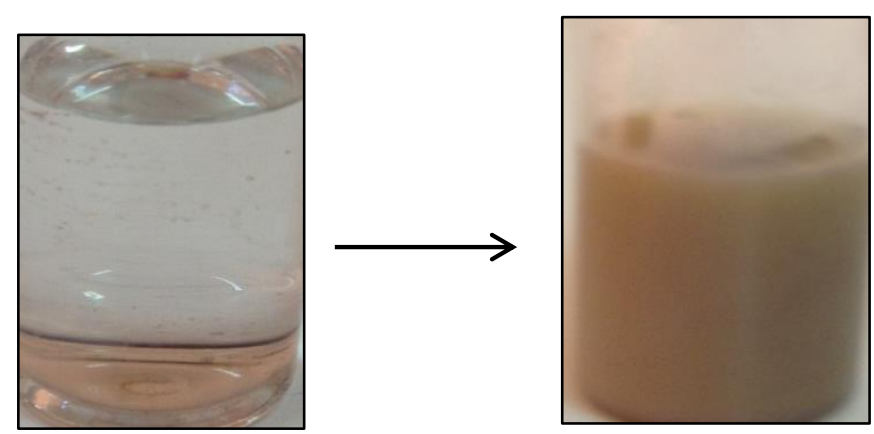

Fig. (1): Shows the presence of nanoparticles in the solution, the color of the solution turned into greenish-yellow, indicating the formation of AgNP.

AgNPs with size $\approx 30 \mathrm{~nm}$ were produced by using ammonia as an oxidizing agent to oxide glucose to gluconic acid by amine that presence in $\mathrm{AgNO}_{3}$.The produced AgNPs capped with gluconic acid that prevent surface oxidation. The diameter of nanoparticles about $30 \mathrm{~nm}$ figure 2 presented SEM image of Ag nanoparticles. AgNPs were synthesized with assisted assay [11,12] which is a rapid method in the process of nucleation metallic nanoparticles like gold and platinum nanoparticles [13]. Since ionic conduction and dipolar mechanism of the chemistry of microwave assist construction of nanoparticles [14, 15] .Radiation by microwave creates the uniform size of nanoparticles owing to the homogeneous heating of the media, that rise the accelerate nucleation reaction of nanoparticles in addition to depletion energy is lower by microwave method in comparison with classical heating method [11,15].

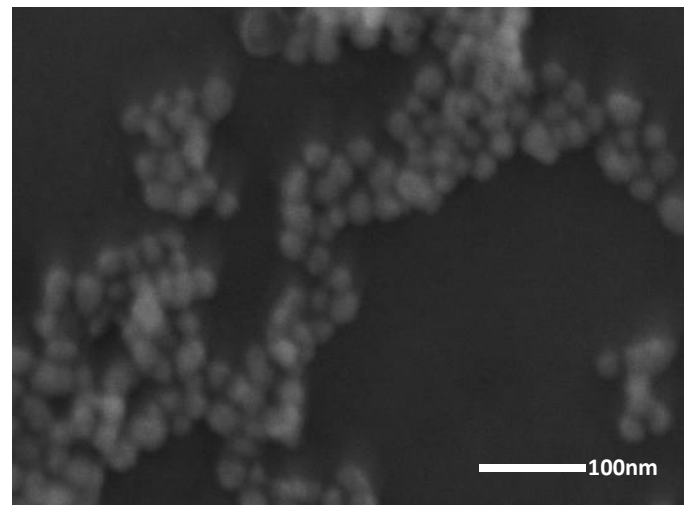

Fig. (2): SEM image of the silver nanoparticles obtained by using glucose and microwave

\section{UV visible spectrophotometry of $\mathrm{Ag}$ nanoparticles and Ag-Amp:}

Figure 3 showed a sharp peak at $408 \mathrm{~nm}$ which indicated that particles produced in monodispersed with spherical shape due to their surface plasmon. Instead figure 4 presented that SPR of AgNP shifted from 408 to 427 $\mathrm{nm}$. Thioether of ampicillin attached antibiotic to silver nanoparticles. The 19 $\mathrm{nm}$ shift in SPR is due to the change in the surface chemistry of NP following the addition of ampicillin 


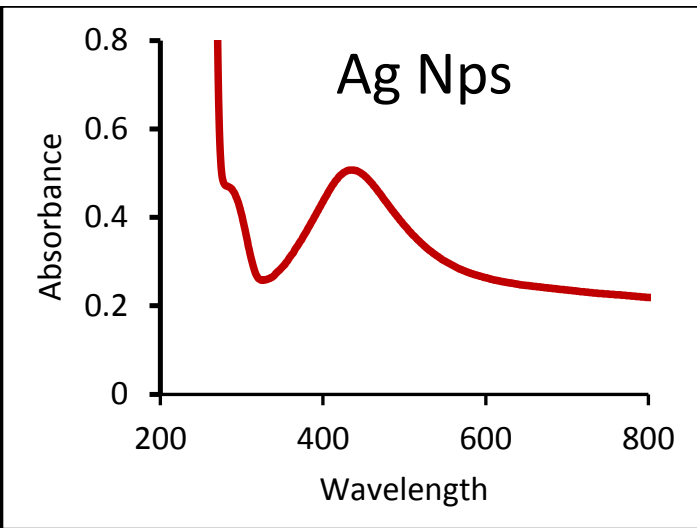

Fig. (3): UV-Vis Absorption spectrum of Ag nanoparticles

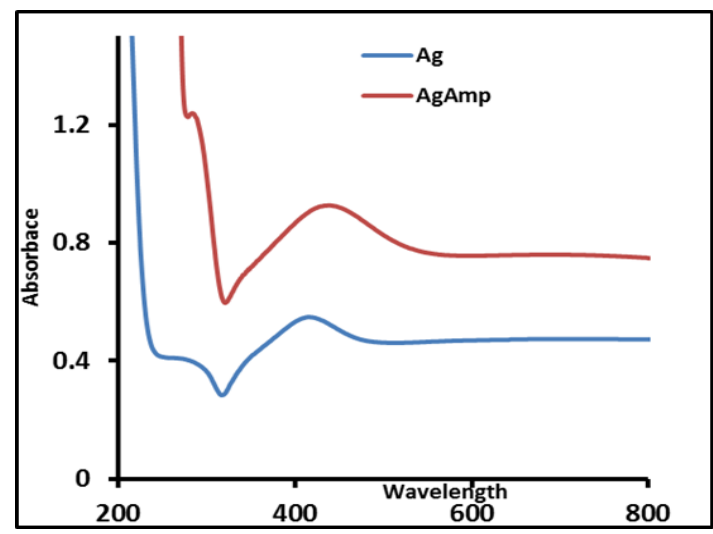

Fig. (4): UV-Visible absorption spectra for AgNPs (left) and Ag nanoparticles (right) before and after ampicillin functionalization

\section{Determine stability of nanoparticles} by Zeta potential

The long-term stability of colloidal AgNPs was checked by zeta potential which shows the changes of

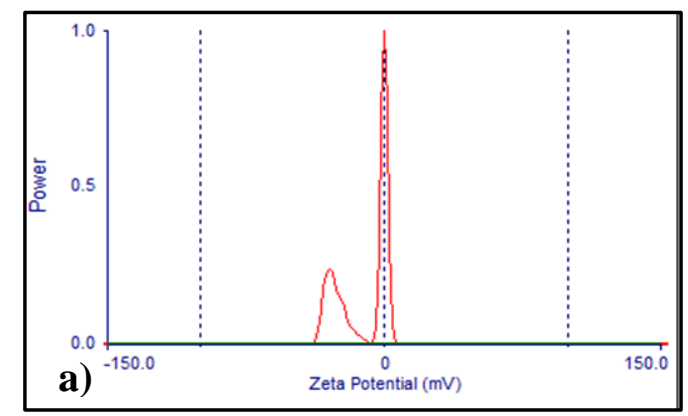

the surface of the AgNPs figure (5).Such technique is generally used to control the stability of colloidal metal nanoparticles [16]. The metal nanoparticles with a large positive or negative zeta potential have a tendency to repel each other and they do not display any disposition to come together. However, in case of low absolute zeta potential values, these particles aggregate and flocculate due to the absence of repulsive force [17]. Zeta potential results of the freshly prepared colloidal AgNPs by using glucose and microwave and AgAmp shown to be having values $-30 \mathrm{mV}$ and $-19 \mathrm{mV}$. It can be seen from the figure that particles prepared using glucose and microwave was stable, and the zeta potential of these samples was somewhat constant within 30 days, and it was more stable when functionalized with Amp, that because Amp work as coating agent that lead to stabilization of the nanoparticles .These, nearly constant, values of zeta potential indicate a longterm stability of the corresponding colloids, which could be due to the gluconic acid that leads to stabilization of the nanoparticles .However, other kinds of preparation are needed for coating agent to prevent AgNPs from aggregations

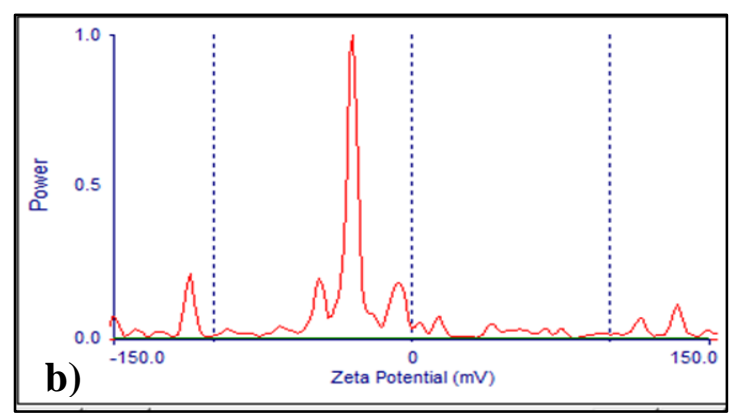

Fig. (5): Zeta potential of the a) freshly prepared colloidal AgNPs by using glucose and microwave and b) AgAmp shown to be having $\zeta$ values $-30 \mathrm{mV}$ and $-19 \mathrm{mV}$. 


\section{FT-IR chemical analysis}

Various peaks were shown by using FTIR spectra,Peaks about 3400 and $1600 \mathrm{~cm}-1$ may be for the hydroxyl groups [18].That may contain in the glucose/gluconic acid.The peak at 1384 $\mathrm{cm}-1$ can be assigned to the nitrate ions We can see peak for gluconic acid even many time of washing silver nanoparticles, thus peaks at 1740,1638 , 1412, 1230, 1100, 1036 and $875 \mathrm{~cm}^{-1}$ may attributed to the gluconic acid. Practically all these peaks perform at the nano silver sample. [19] figure (6a). To appreciate the binding mechanism of the surface modification of the silver nanoparticles, FTIR spectra of the silver NPs and modified silver nanoparticles with ampicillin were examined as shown in Figure $(6 b)$ For the modified silver nanoparticles, a band was observed at $3500 \mathrm{~cm}^{-1}$ that correspond to the stretching of the $\mathrm{N}-\mathrm{H}$ bond and two other shoulder peaks at $1600 \mathrm{~cm}^{-1}$ and $1200 \mathrm{~cm}^{-1}$ related to the stretching of the $\mathrm{C}=\mathrm{O}$ bond and the flexion of the $\mathrm{N}-$ $\mathrm{H}$ bond. and the presence of these bands confirms that the silver is effectively functionalized with the ampicillin. These results are in good agreement with those reported previously by [20] who made the surface modification of magnetic nanoparticles with a similar silane compound using a molar ratio of 1: 0.5 (nanoparticles : silane).

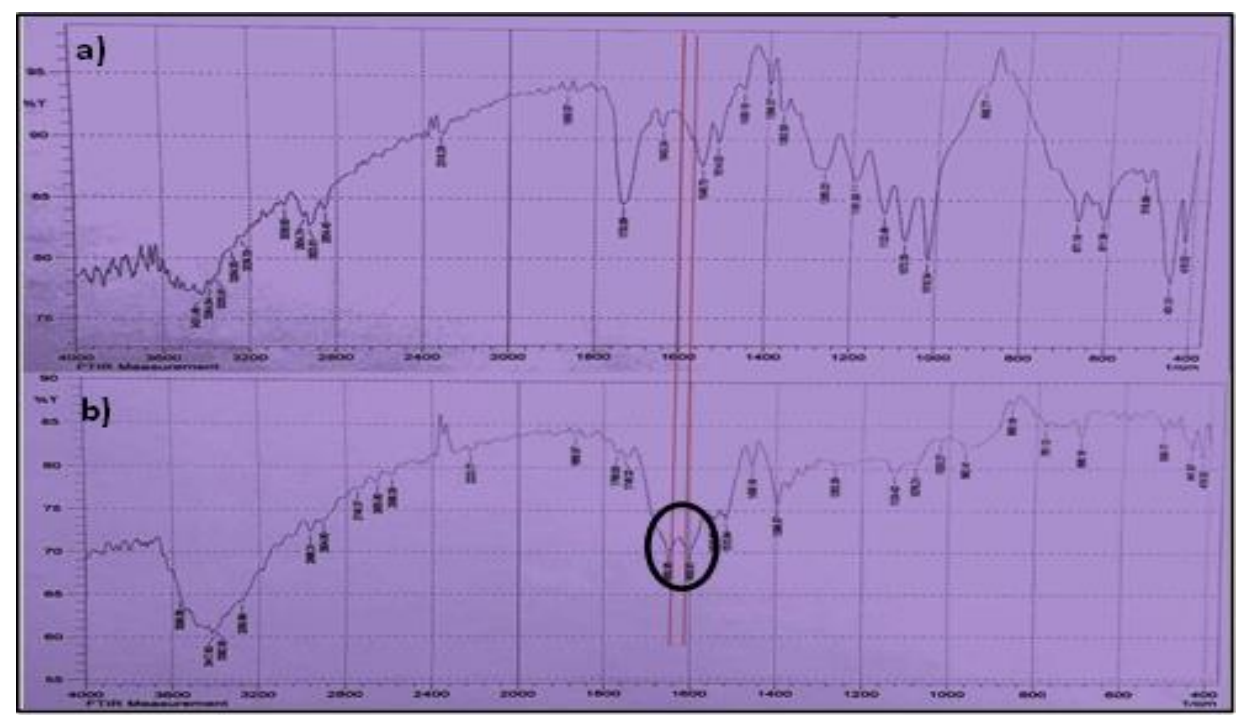

Fig. (6 a;b): FTIR spectra for the silver nanoparticles a) before and b) after modified with ampicillin

\section{Agar disks diffusion test}

In this study, the prepared AgNPs and Ag-AMP samples have been used to study antibacterial activity against E. coli, S.aureus and A.baumannii as shown in table (1). Ampicillin, Ag-AMP and silver nanoparticles (prepared from glucose). The results showed that there were no effect of ampicillin on different types of bacteria. For Ag-Amp with Amp concentration $20+1.06 * 10^{6} \mathrm{~mol}$ showed inhibition zone (nm) 17,27 and
$15 \mathrm{~nm}$ for E. coli, S.aureus and A.baumannii respectively.Also different concentrations of AgNPs which were 4, 8 and $16 \mu \mathrm{g} / \mathrm{ml}$ were tested ,the minimum concentration $(4 \mu \mathrm{g} / \mathrm{ml})$ was not showed any effect on the different kinds of bacteria, whereas $8 \mu \mathrm{g} / \mathrm{ml}$ showed 8,6 and $10 \mathrm{~mm}$ and for 16 $\mu \mathrm{g} / \mathrm{ml}$ the inhibition zones were 16,11 and $19 \mathrm{~mm}$ for E. coli, S.aureus and A.baumannii respectively 
Table (1): Zone inhibition of antibacterial test of Ag and Ag-Amp

\begin{tabular}{|c|c|c|c|c|}
\hline \multirow{2}{*}{$\begin{array}{c}\text { Bioactive } \\
\text { agent }\end{array}$} & \multirow{2}{*}{ concentration } & \multicolumn{3}{|c|}{ Zone of inhibition (Diameter, mm) } \\
\cline { 3 - 5 } & E.coli & S.aureus & A.baumannii \\
\hline Ampicillin & 0 & 0 & 0 & 0 \\
\hline Ag-Amp & $\begin{array}{c}20+1.06 * 10^{6} \\
\text { mol }\end{array}$ & 17 & 27 & 15 \\
\hline & $4 \mu \mathrm{g} / \mathrm{ml}$ & 0 & 0 & 0 \\
\hline Ag NPs & 8 & 8 & 6 & 10 \\
\hline & 16 & 16 & 11 & 19 \\
\hline
\end{tabular}

\section{Minimum Inhibitory concentration (MIC)}

Table (2) shows the MICs of AgNPs prepared from glucose, samples Nos. 1, 2 and 3 against the individual tested bacterial strains. These results tend to indicate that the AgNPs had different anti-bacterial activity against Staphylococcus aureus, E.coli and Acinetobacter. The MIC observed in this study for silver nanoparticles prepared from glucose, are $20 \mu \mathrm{g} / \mathrm{ml}, 40$ $\mu \mathrm{g} / \mathrm{ml}, 80 \mu \mathrm{g} / \mathrm{ml}$ respectively against $S$. aureus. In case of E.coli MIC were 80 $\mathrm{mg} / \mathrm{mL}, 160 \mathrm{mg} / \mathrm{mL}, 320 \mathrm{mg} / \mathrm{mL}$, While for A.baumannii are $40 \mathrm{mg} / \mathrm{mL}, 80$ $\mathrm{mg} / \mathrm{mL}, 160 \mathrm{mg} / \mathrm{mL}$. From the latter results, it is clear that Staphylococcus aureus sensitive to silver NPs because the formation of biofilm surrounded the bacterial cell and accumulation of nanopartiles inside it, while $E$. coli, A.baumannii were need more concentrations of AgNPs to produce more silver ions to effect on bacteria, therefore AgNps had higher antibacterial activity against S.aureus than A.baumannii, E. coli .

Table (2) : MICs of AgNPs prepared from glucose

\begin{tabular}{|c|c|c|c|}
\hline \multirow{3}{*}{ Sample } & \multicolumn{3}{|c|}{ Minimum inhibition concentration $(\boldsymbol{\mu g} / \mathbf{m l})$} \\
\cline { 2 - 4 } & S.aureus & E.coli & A.baumannii \\
\cline { 2 - 4 } & 20 & 80 & 40 \\
\hline \multirow{3}{*}{ AgNPs } & 40 & 160 & 80 \\
\cline { 2 - 4 } & 80 & 320 & 160 \\
\hline
\end{tabular}

\section{Conclusions:}

From the current investigations successfully prepared of AgNPs by green method with $30 \mathrm{~nm}$.As well as Amp was successfully functionalized surface of nanoparticles. AgNPs presented potential antibacterial activity, against three different bacteria like Escherichia coli, S.aureus and A.baumannii. $\mathrm{Ag}$ and Ag-AMP nanoparticles were detected to have penitent antimicrobial, the effects were compared with the result of antibiotics alone like ampicillin, the results indicated that Ag-AMP more potent than antibiotics.

\section{References:}

[1] Hussein-Al-Ali S. H.; El Zowalaty M. E.; Hussein M. Z.; Geilich B. M. and Webster T. J. 2014. Synthesis; characterization; and antimicrobial activity of an ampicillin-conjugated magnetic nanoantibiotic for medical applications; Journal of Nanomedicine 8(9):3801-149.

[2] Davies J. and Davies D. 2010. Origins and Evolution of Antibiotic Resistance. Microbiol. Mol. Biol. Rev., 74 (3): 417-433.

[3] Brown A. N.; Smith K.; Samuels T. A.; Lu J.; Obare S. O. and Scott M. E. 2012. nanoparticles functionalized with ampicillin destroy multiple-antibioticresistance isolates of pseudomonas aeruginosa and enterobacter aerogenes and methicillin - resistant staphylococcus aureus. Appl Environ Microbiol.78(8) :2768

[4] Xie Y.; He Y.; Irwin P. L.; Jin T. and Shi X. 2011. Antibacterial Activity and Mechanism of Action of Zinc Oxide Nanoparticles against Campylobacter jejuni. Journal of Applied Environment Microbiology. 77(7): 2325-2331.

[5]Hajipour M. J.; Fromm K. M.; Ashkarran A. A.; de Aberasturi D. J.; de Larramendi I. R.; Rojo, T.; Serpooshan V.; Parak W. J. and Mahmoudi M. 2012. Antibacterial properties of nanoparticles .Trends in Biotechnology 30: 499-511 
[6]Chook S. W.; Chia C. H.; Zakaria S., Ayob MK.; Chee KL.; Huang NM.; Neoh HM.; Lim HN.; Jamal R.and Abdul Rahman RM.FR. 2012. Antibacterial performance of $\mathrm{Ag}$ nanoparticles and AgGO nanocomposites prepared via rapid microwave-assisted synthesis method. Nanoscale Research Letters 7:541

[7] Bonev et al. 2008. Principles of assessing bacterial susceptibility to antibiotics using the agar diffusion method. Journal of Antimic. Chemotherapy., 61(6).

[8]Emanuel, G. and Lorrence, H. 2008. Practical Handbook of Microbiology, Second Edition (Google eBook) (Second Edition ed.). USA: CRC Press, Taylor and Francis Group. p. 864.

[9]Miles R.S. and Amyes S.G.B. 1996. Laboratory control of antimicrobial therapy. In: Collee J. G.; Fraser A. G.; Marmino B. P.; Simons A. (eds) Mackie \& McCartney's Practical Medical Microbiology, Churchill Livingstone, New York, pp. 151-177.

[10] Haiss W.; Thanh N.T.K.; Aveyard J. and Fernig D.G. 2007. Determination of size and concentration of gold nanoparticles from UV-Vis spectra. Journal of Analytical Chemistry 79: 4215-4221.

[11] Choi O.; Ding K.; Kim N.; Ross Jr. L.; Surampalli R. and Hu Z. 2008. The inhibitory effects of silver nanoparticles; silver ions; and silver chloride colloids on microbial growth. Water Res 42:3066-3074.

[12] Ciptadjaya, C. G.; Guo, W.; Angeli, J. M. and Obare, S. O. 2009. Controlling the reactivity of chlorinated ethylenes with flavin mononucleotide hydroquinone. Journal of Environment Science Technology. 43:1591-1597.

[13] Cobley C. M.; Chen J.; Cho E. C.; Wang, L. V. and Xia Y. 2011. Gold nanostructures: a class of multifunctional materials for biomedical applications. Journal of Chemistry Society .40:44 -56.

[14] Fako, V. E.; Furgeson D. Y. 2009. Zebrafish as a correlative and predictive model for assessing biomaterial nanotoxicity. AJADD 61:478-486.

[15] Fayaz, A.M.; Kulandaivelu, Balaji, K.; Morukattu, Girilal, M.; Yadav R.; Kalaichelvan P.T. and Venketesan, R. 2010. Biogenic synthesis of silver nanoparticles and their synergistic effect with antibiotics: a study against grampositive and gram negative bacteria. Journal of Nanomedicine 6:103-109.

[16] Huang, K.; Ma H.; Liu J. 2012. Size-dependent localization and penetration of ultrasmall gold nanoparticles in cancer cells; multicellular spheroids; and tumors in vivo. Journal of ACS Nano. 6(5):4483-4493.

[17] Abou El-Nour, K.M.M.; Eftaiha, A.; Al-Warthan, A. and Ammar, R. A. 2010. Synthesis and applications of silver nanoparticles. Arabian Journal of Chemistry 3(3): 135-140

[18] Janardhanan, R.; Karuppaiah, M.; Hebalkar, N. and Narsinga, T. 2009. Synthesis and surface chemistry of nano silver particles. Journal of Polyhedron. 28(12):252230

[19] Kong, J. and Yu, S. 2007. Fourier Transform Infrared Spectroscopic Analysis of Protein Secondary Structures. Acta Biochimica et Biophysica Sinica, 39(8): 549-559.

[20] Rodr'1guez, O.S.; Castellanos, F. Y.; Betancourt R. and Yãnez I. G. 2009. A new class of polyvinylcloride nanocomposite based on magnetic nanofillers and plastisols in Proceedings of the 67th Annual Technical Conference of the Society of PlasticsEngineers (ANTEC '09) 438-441. 


\title{
التحري عن الفعالية المضادة للبكتريا لاقائق الفضة النانوية المحضرة بالطريقة

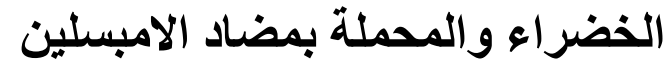

\author{
| - اسراء علي زيدان العكيدي
}

قسم التقنيات الاحيائية، كلية العلوم، جامعة بغداد، بغداد، العراق

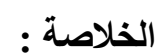

في الدر اسة الحالية، تم تصنيع وتوصيف دقائق الفضة النانوية مع در اسة تطبيقاتها على البكتريا الممرضئ.

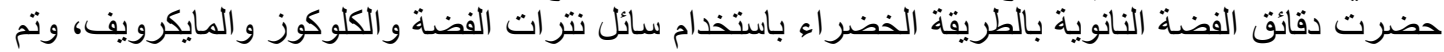

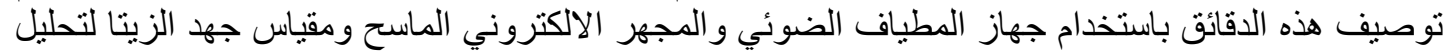

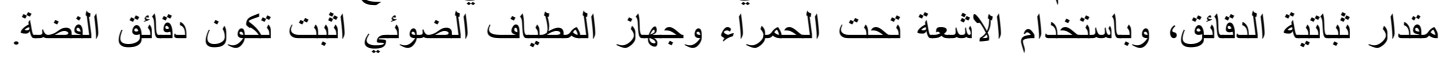

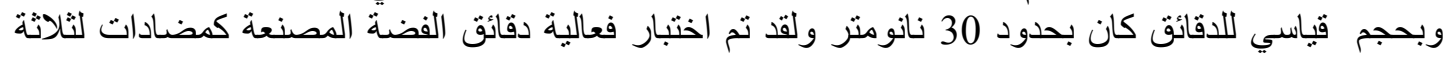

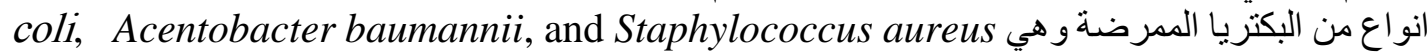
Escherichia

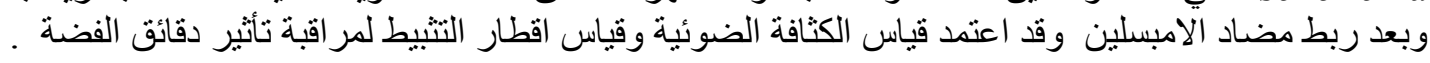
الكلمات المفتاحية:دقائق الفضة النانوية، التصنيع البايلوجي، مضاد للبكتريا، الكلوكوز، مايكرويف 